Please quote as: Pressler, A.; Knebel, U.; Esch, S.; Kölbl, D.; Esefeld, K.; Scherr, J.; Haller, B.; Schmidt-Trucksäss, A.; Krcmar, H.; Halle, M. \& Leimeister, J. M. (2010): An internet-delivered exercise intervention for workplace health promotion in overweight sedentary employees: A randomized trial. In: Preventive Medicine, Ausgabe/Number: 51, Verlag/Publisher: Elsevier. Erscheinungsjahr/Year: 2010. Seiten/Pages: 234-239. 
Provided for non-commercial research and education use. Not for reproduction, distribution or commercial use.

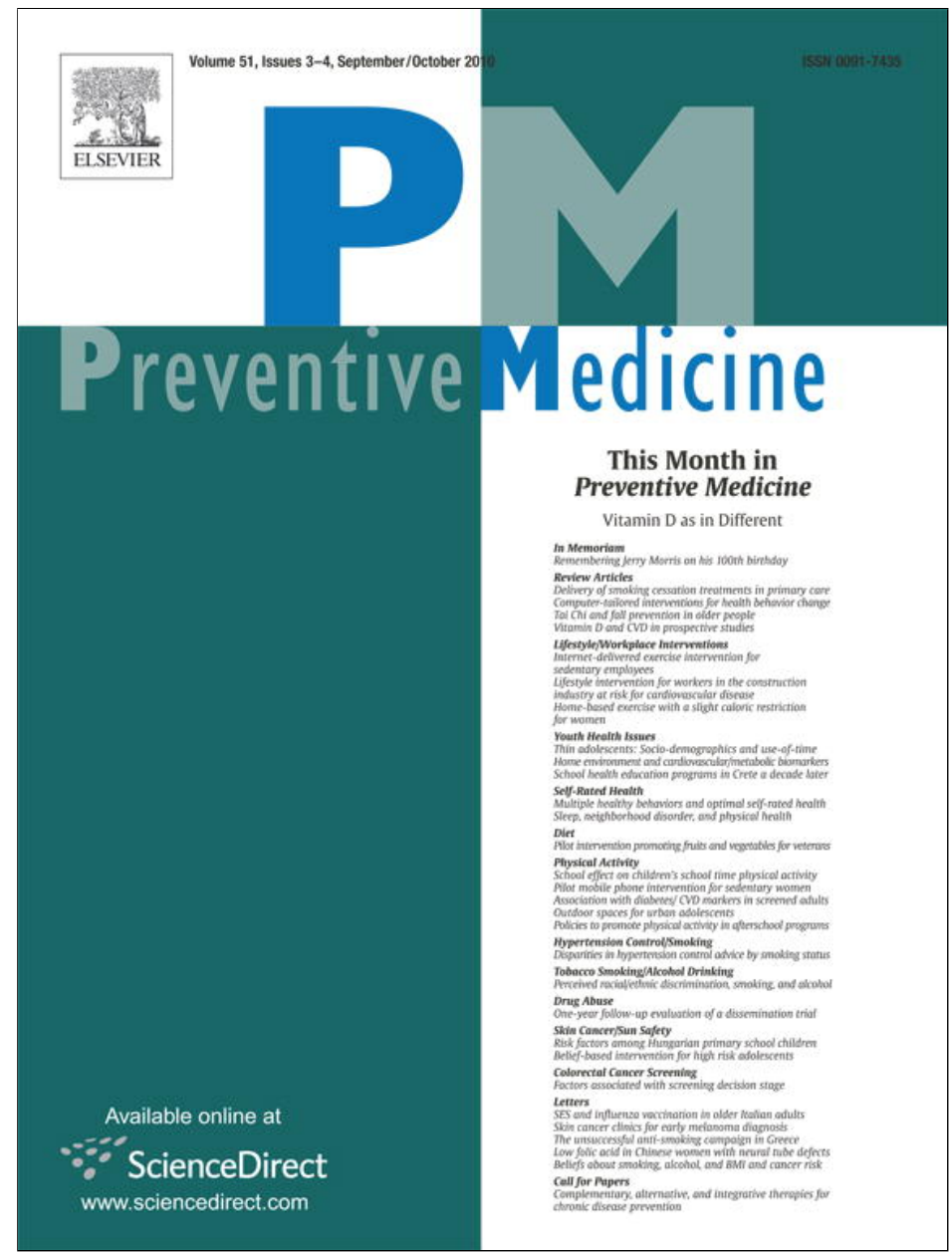

This article appeared in a journal published by Elsevier. The attached copy is furnished to the author for internal non-commercial research and education use, including for instruction at the authors institution and sharing with colleagues.

Other uses, including reproduction and distribution, or selling or licensing copies, or posting to personal, institutional or third party websites are prohibited.

In most cases authors are permitted to post their version of the article (e.g. in Word or Tex form) to their personal website or institutional repository. Authors requiring further information regarding Elsevier's archiving and manuscript policies are encouraged to visit:

http://www.elsevier.com/copyright 


\title{
An internet-delivered exercise intervention for workplace health promotion in overweight sedentary employees: A randomized trial
}

\author{
Axel Pressler ${ }^{\mathrm{a}, *}$, Uta Knebel $^{\mathrm{b}}$, Sebastian Esch ${ }^{\mathrm{b}}$, Dominik Kölbl ${ }^{\mathrm{a}}$, Katrin Esefeld ${ }^{\mathrm{a}}$, Johannes Scherr ${ }^{\mathrm{a}}$, \\ Bernhard Haller ${ }^{c}$, Arno Schmidt-Trucksäss ${ }^{\mathrm{a}, \mathrm{d}}$, Helmut Krcmar ${ }^{\mathrm{b}}$, Martin Halle ${ }^{\mathrm{a}}$, Jan Marco Leimeister ${ }^{\mathrm{e}}$ \\ a Department of Prevention and Sports Medicine, Technische Universität München, Connollystr. 32, 80809 München, Germany \\ ${ }^{\mathrm{b}}$ Department of Information Systems, Technische Universität München, Boltzmannstr. 3, 85748 München, Germany \\ c Department of Medical Statistics and Epidemiology, Technische Universität München, Ismaninger Str. 22, 81675 München \\ ${ }^{d}$ Department of Sports Sciences and Sports Medicine, Universität Basel, Birsstr. 320b, 4052 Basel, Switzerland \\ e Information Systems/Research Center for IS Design (ITeG), Universität Kassel, Nora-Platiel-Str. 4, 34127 Kassel, Germany
}

\section{A R T I C L E I N F O}

Available online 16 July 2010

\section{Keywords:}

Internet

Exercise

Metabolic syndrome

\section{A B S T R A C T}

Objective. To evaluate the effect of structured vs. non-structured internet-delivered exercise recommendations on aerobic exercise capacity and cardiovascular risk profile in overweight sedentary employees.

Methods. 140 employees of an automobile company (11\% female, median age 48 years (range 25-60), BMI $29.0 \mathrm{~kg} / \mathrm{m}^{2}$ (25.0-34.8)) were randomized in a 3:2 ratio to an intervention group receiving structured exercise schedules or a control group choosing workouts individually via an interactive website. The 12 week intervention took place in Munich, Germany, during summer 2008. Main outcome measure was performance at the lactate anaerobic threshold $\left(P_{\mathrm{AT}} / \mathrm{kg}\right)$ during ergometry.

Results. 77 participants completed the study. The intervention group $(n=50)$ improved significantly in $\mathrm{P}_{\mathrm{AT}} / \mathrm{kg}((\operatorname{mean}(\mathrm{SD})) 1.68$ (0.31) vs. $1.81(0.33) \mathrm{W} / \mathrm{kg} ; p=0.002), \mathrm{VO}_{2}$ peak (3.21 (0.63) vs. $3.35(0.74) \mathrm{L} /$ min; $p=0.04)$, and waist circumference (100.5 (7.9) vs. 98.0 (7.8) $\mathrm{cm} ; p=0.001)$. The control group $(n=27)$ improved significantly in $\mathrm{P}_{\mathrm{AT}} / \mathrm{kg}(1.59(0.38)$ vs. $1.80(0.49) ; p<0.001)$ and waist circumference (101.9 (8.7) vs. $98.3(8.5) \mathrm{cm} ; p<0.001)$, but not in $\mathrm{VO}_{2}$ peak. No significant between group differences in these outcome measures were noted.

Conclusion. Structured, internet-delivered exercise recommendations are not superior to internetdelivered non-structured exercise recommendations in a workplace setting. Both lifestyle intervention strategies are, however, limited by high dropout rates.

(c) 2010 Elsevier Inc. All rights reserved.

\section{Introduction}

Obesity and physical inactivity are important risk factors for developing cardio-metabolic disorders (Haslam and James, 2005; Kodama et al., 2009; LaMonte et al., 2005b). Facing their dramatic increase in recent decades there is clear scientific consensus to promote physical activity (Haskell et al., 2007; Marcus et al., 2006). Although large trials on structured lifestyle interventions have shown beneficial effects on preventing metabolic diseases such as

* Corresponding author. Department of Prevention and Sports Medicine, Technische Universität München, Connollystr. 32, 80809 München, Germany. Fax: +49 89289 24451.

E-mail addresses: pressler@sport.med.tum.de (A. Pressler), uta.knebel@in.tum.de (U. Knebel), esch@in.tum.de (S. Esch), dominik.koelbl@mytum.de (D. Kölbl), esefeld@sport.med.tum.de (K. Esefeld),scherr@sport.med.tum.de (J. Scherr) bernhard.haller@tum.de (B. Haller), arno.schmidt-trucksaess@unibas.ch (A. Schmidt-Trucksäss), krcmar@in.tum.de (H. Krcmar), halle@sport.med.tum.de (M. Halle), leimeister@in.tum.de (J.M. Leimeister). type 2 diabetes mellitus (Knowler et al., 2002; Tuomilehto et al., 2001), their transfer into a real-life setting often depends on sufficient human or financial resources. The internet has been discussed as a promising tool to reduce these limitations by replacing procedures that can be standardized within an intervention and by reaching large numbers of subjects at low costs (van den Berg et al., 2007; Vandelanotte et al., 2007). Therefore, efforts have been intensified during recent years to determine the effectiveness of internet-delivered lifestyle interventions (Marcus et al., 2009). In fact, commercial internet-delivered exercise programs are already ubiquitously available, but there is still limited scientific evidence for their efficacy in primary prevention.

An opportunity to reach large cohorts of sedentary subjects at increased metabolic risk is the workplace. As internet access is widely available there (Marcus et al., 2006), this study investigated the application of an internet platform in a large company to deliver exercise recommendations for health promotion. The aim was to improve exercise capacity and metabolic risk profile determined by 
objective measurements in overweight, sedentary employees. It was hypothesized that delivering a structured exercise intervention via an internet platform is superior regarding these goals than a nonstructured program.

\section{Methods}

Participants

For participant recruitment data were used from a health survey conducted several weeks prior to initiation of the study in employees of a large German automobile manufacturer. Study inclusion criteria were: overweight and obesity defined as a body mass index (BMI) of 25-35 kg/ $\mathrm{m}^{2}$, sedentary life-style (self-reported physical activity $<1 \times /$ week), age 20 60 years, and $\geq 2$ metabolic syndrome risk factors (National Cholesterol Education Program (NCEP) Expert Panel, 2002). The company's health care department supported the study and performed data selection and e-mail contact. However, according to the company's privacy policy data were not available for further analysis. During the study period there were approximately 31,000 employees (13\% female) with the majority ( $80 \%)$ working in fields of research and design.

Participants meeting the inclusion criteria were contacted via e-mail and provided with detailed information on the study. No reminder e-mails were sent. For participation the employees were asked to register on the welcome page of the program. After receiving a password, participants completed the Physical Activity Readiness Questionnaire to detect any exercise-associated medical problems (Shephard, 1988); a pre-participation health screening by a general practitioner was necessary if any responses were affirmative. Subsequently, eligible participants were consecutively randomized in the order of their online registration and allocated to an intervention group (IG) receiving structured exercise schedules or to a control group (CG) exercising on a voluntary basis according to prior standard advice.

The study protocol was approved by the local ethics committee of the university hospital. Written informed consent was obtained from study participants before baseline examinations.

\section{Intervention}

Study duration was 12 weeks. All participants (IG and CG) had free access to the internet via their personal workplace. The intervention comprised an initial education session, a structured (IG) or non-structured (CG) internetdelivered exercise program and a final education session (Knebel et al., 2009). The initial education sessions included lectures on medical risks of obesity and inactivity (20 min), general advice on appropriate exercise duration and intensity ( $25 \mathrm{~min}$ ), and introductory lessons on structure and use of the internet platform (30 min). The sessions were separated for both groups due to the different content of the internet platform.

Participants randomized to the IG received a structured exercise schedule via the internet for the entire study period. The schedule comprised three moderate endurance workouts per week which increased in time from 30 to $70 \mathrm{~min}$ ( 105 to $165 \mathrm{~min}$ per week) and one additional strength training session per week (altogether 48 workouts). Warm-upand cool-down-phases were included in each workout. Strength training could either be performed home-based by realizing exercises presented photogenically via the internet platform or in the company's (or external) fitness center. The exercise schedule was presented as a calendar function via an interactive website with the possibility to postpone or cancel workouts in a defined, limited frame. Participants could choose between previously defined endurance sports (e.g. cycling, walking, and swimming) via a drop-down menu. Additional activities such as ball sports were also offered in the menu but were not part of the schedule. Exercise intensities were defined based on the initial exercise testing using Karvonen's equation with a multiplier of 0.5-0.6 (Karvonen et al., 1957), corresponding to approximately $60-70 \%$ of maximum heart rate. This exercise heart rate was automatically presented for each exercise session and was adjusted according to the chosen type of endurance activity to consider different circulatory demands (e.g. $+10 \mathrm{bpm}$ for running vs. cycling). Participants were asked to document their resting heart rate weekly to adapt the intensities to the training status using Karvonen's equation. Pulse rate was monitored by a heart rate monitor (FS2c, Polar, Finland) to control exercise intensity; participants were provided with a brief manual on how to use the monitor. Weekly exercise goals were established, based on exercise duration and intensity according to metabolic equivalent tasks (Ainsworth et al., 2000). The 12-week goal was to increase activity up to 1500 MET*min/week aiming at doubling the minimum exercise requirements in primary prevention (Haskell et al., 2007). To reach goals, at least $75 \%$ of the weekly exercise sessions had to be completed. This was documented by each individual by actively deactivating the time slot of each exercise session. Participants not deactivating their workouts had to repeat the particular week, ensuring that participants followed their endurance exercise schedule. All exercise sessions were planned as individual workouts; no group sessions were provided.

Participants randomized to the CG had access to the same internet platform, but were only provided with an empty calendar function and the above-mentioned drop-down-menu and not with a structured schedule. Exercise sessions had to be chosen individually according to standard advice; weekly goals were not established. However, participants were also asked to document workouts in their personal calendar on the internet platform. Participants in the CG were also provided with a heart rate monitor but received their individual exercise intensity only once at the beginning of the intervention.

Participants of both groups were offered a membership in the company owned fitness center at a reduced price during the entire study period. However, exercise was not supervised or coached in any group. All participants were blinded to group assignment.

During the final education session exercise-related problems were discussed, lactate curves were explained, and participants received advice on how to continue with regular exercise activities beyond the study period.

\section{Outcome measures}

Primary outcome measure was the difference in increase of weightadjusted performance at the lactate anaerobic threshold $\left(P_{\mathrm{AT}} / \mathrm{kg}\right)$, representing an improvement in aerobic exercise capacity. Secondary outcome measures included peak oxygen uptake $\left(\mathrm{VO}_{2}\right.$ peak), peak ergometer performance $\left(P_{\mathrm{MAX}} / \mathrm{kg}\right)$, and heart rate during ergometry. The following metabolic parameters were also assessed: waist circumference, body mass index (BMI), body fat composition, resting blood pressure, high-density lipoprotein cholesterol (HDL), triglycerides, and fasting blood glucose. Acceptance of the intervention was assessed by a final questionnaire using 5 -point-scales ( $1=$ not true; $5=$ completely true) for the statements "I liked the program" and "I feel more active". In addition, participants were asked to assign school grades for the whole intervention from 1 to 6 ( $1=$ very good; $6=$ inadequate).

Measures of height, weight, body fat, blood pressure, and serum lipids were recorded at baseline using standard accepted techniques. Body fat was measured using a bio-impedance-monitor (BF500, Omron, Kyoto, Japan (Minderico et al., 2008)), and waist circumference was assessed according to current guidelines (Graham et al., 2007). Blood pressure was measured in resting supine position. Venous blood samples were taken in a fasting condition and analysed for HDL, triglycerides, and blood glucose. Symptomlimited exercise tests were performed on standard bicycle ergometers (Technogym, Egelsbach, Germany), starting at $50 \mathrm{~W}$ and increasing by $30 \mathrm{~W}$ every $3 \mathrm{~min}$. Capillary blood samples were taken at rest and at the end of each step during exercise. Along with incremental heart rates lactate curves were fitted using Ergonizer Software (Röcker K., Freiburg, Germany). The individual anaerobic threshold was determined using the method described by Dickhuth et al (Dickhuth et al., 1991). Simultaneously, peak oxygen uptake was measured by spiroergometry (Metalyzer, Cortex, Leipzig, Germany). Physical activity level was assessed using pedometers (Pedometer Plus, Silva, Sollentuna, Sweden) with daily step counts averaged out of 7 days as outcome measure.

\section{Sample size}

Assuming a standard deviation of $0.25 \mathrm{~W} / \mathrm{kg}$, the study was powered at $80 \%$ to detect a difference in the increase in performance at the anaerobic threshold of at least $0.15 \mathrm{~W} / \mathrm{kg}$ using a two-sided level of significance of $\alpha=5 \%$. To account for high drop-out rates reported in similar studies (Slootmaker et al., 2009; Spittaels et al., 2007b; Verheijden et al., 2007; Ware et al., 2008), the sample size was increased by 40\% (=140 participants). Participants were randomly allocated to the two groups in a 3:2 ratio (IG:CG) in order to increase information on a structured exercise intervention (60 persons had to be allocated to the IG and 40 to the $(G)$. 


\section{Statistical analysis}

The primary endpoint was examined with an independent sample t-test. All analyses were performed two-sided using a $5 \%$ level of significance. Secondary variables were analysed in an explorative manner: no adjustment for multiple testing was conducted. Paired $t$-tests were performed to compare values before and after intervention, independent sample $t$-tests were used to test for inequality of means of post-intervention to baseline differences between the two treatment groups. Differences between the two measurements were normally distributed and are presented as mean \pm standard deviation. Fisher's exact test was used for comparison of proportions in the treatment groups. All data analyses were performed with PASW versions 17.0 and 18.0 (SPSS Inc., Chicago; IL, USA).

\section{Results}

\section{Participants}

A total of 1,380 employees were contacted per e-mail. Within 2 weeks, the required 140 participants had registered and were subsequently randomized. Of these, 105 actually entered baseline examinations and were used for the study population (median age 48 years (range $25-60$ ), $11 \%$ female, BMI $29.0 \mathrm{~kg} / \mathrm{m}^{2}$ (25.0-34.8)). 35 participants did not show up for baseline examination. If available, reasons given for withdrawing the registration were lack of time, lack of further interest or medical problems detected by the PAR-Q questionnaire. At baseline, there were no significant differences between the IG and the CG in any of the outcome measures. 23 participants registered for the company's fitness center ( $I G=12$, $\mathrm{CG}=11 ; p=0.33$ ). Further details on participant flow are summarized in Fig. 1.
Exercise capacity and metabolic risk factor measurement outcomes

Results of the primary outcome measure, weight-adjusted performance at the anaerobic lactate threshold $\left(\mathrm{P}_{\mathrm{AT}} / \mathrm{kg}\right)$, showed significant increases in both IG and CG between baseline and 12 weeks (Table 1 ). There was a non-significant mean difference of $0.08 \mathrm{~W} / \mathrm{kg}$ between the groups ( $p=0.18 ; 95 \% \mathrm{CI}-0.20$ to 0.04 ).

Significant improvements in secondary outcome measures were found in both groups as shown in Table 1. While peak oxygen uptake $\left(\mathrm{VO}_{2}\right.$ peak) improved significantly in the IG, minimal change over time was found in the CG. Contrastingly, changes in peak ergometer performance $\left(\mathrm{P}_{\mathrm{MAX}} / \mathrm{kg}\right)$ showed slight improvement in the IG, but improvement was significant in the CG. Reduction in heart rate during bicycle ergometry was significant in the IG whereas changes in heart rate were minimal in the CG. A significant decrease in waist circumference from baseline to study end was shown in both the IG and the CG. Participants in the CG showed a significant reduction in both BMI and body fat which was accompanied by a significant decrease over time in blood glucose levels and diastolic blood pressure. The number of daily step counts increased only in the IG but did not reach statistical significance. When comparing the mean differences in increase between the groups in any of the outcome measures, neither exercise strategy showed clear superiority except for a significant decrease of body fat in the CG $(p=0.04)$.

Of the participants registered at the company's fitness center, 21 (91\%) completed the intervention ( $I G=12, C G=9 ; p=0.43$ ). There was no significant difference in the outcome measures between members of the fitness center and non-members except for a significant decrease of body fat $(p=0.005)$.

Of the whole study population (IG and CG), 56 participants (72.7\%) basically increased their performance at the anaerobic threshold.

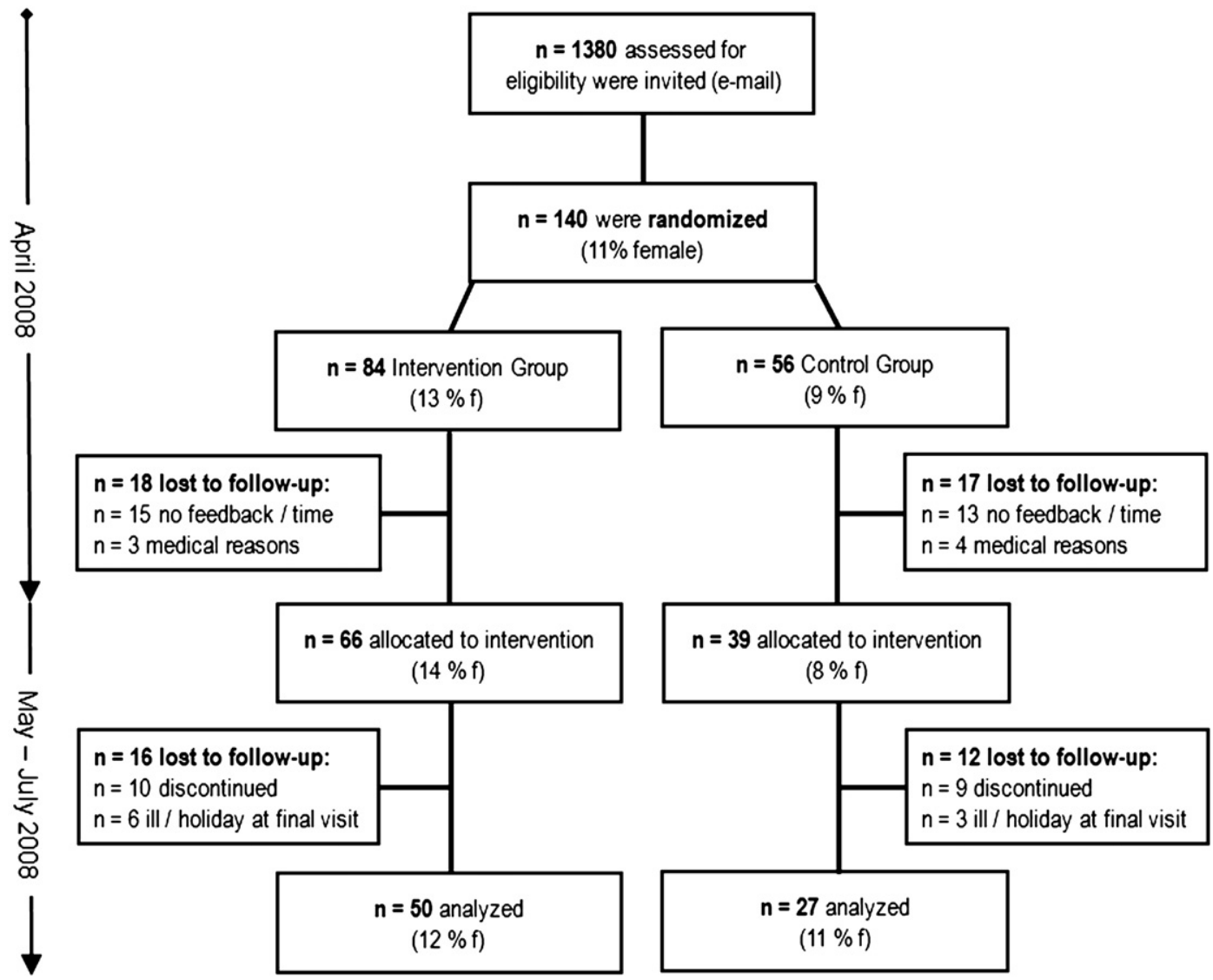

Fig. 1. Flow of participants through the trial. The study was conducted in Munich, Germany, from April through July 2008. 
Table 1

Results of study groups.

\begin{tabular}{|c|c|c|c|c|c|c|}
\hline \multirow[t]{2}{*}{ Outcome measures } & \multicolumn{3}{|c|}{ Intervention group $(n=50)$} & \multicolumn{3}{|c|}{ Control group $(n=27)$} \\
\hline & Baseline & Final & $p$ Value & Baseline & Final & $p$ Value \\
\hline $\mathrm{P}_{\mathrm{AT}} / \mathrm{kg}, \mathrm{W} / \mathrm{kg}$ & $1.68(0.31)$ & $1.81(0.33)$ & 0.002 & $1.59(0.38)$ & $1.80(0.49)$ & $<0.001$ \\
\hline BMI, $\mathrm{kg} / \mathrm{m}^{2}$ & $28.6(1.9)$ & $28.3(2.0)$ & 0.12 & $28.8(2.5)$ & $28.4(2.4)$ & 0.002 \\
\hline WC, $\mathrm{cm}$ & $100.5(7.9)$ & $98.0(7.8)$ & 0.001 & $101.9(8.7)$ & $98.3(8.5)$ & $<0.001$ \\
\hline Body fat, \% & $30.1(5.2)$ & $29.2(5.7)$ & 0.22 & $31.3(6.6)$ & $28.2(5.6)$ & 0.001 \\
\hline $\mathrm{RR}, \mathrm{mmHg}$ & $137 / 87(16 / 11)$ & $136 / 85(13 / 9)$ & $0.85 / 0.12$ & $140 / 89(14 / 10)$ & $138 / 85(12 / 7)$ & $0.41 / 0.03$ \\
\hline $\mathrm{HDL}, \mathrm{mg} / \mathrm{dl}$ & $45.4(10.0)$ & $47.8(9.6)$ & 0.11 & $49.0(11.3)$ & $50.4(11.6)$ & 0.12 \\
\hline Triglyzerides, mg/dl & $158(78)$ & $156(79)$ & 0.86 & $189(131)$ & $192(113)$ & 0.89 \\
\hline Glucose, $\mathrm{mg} / \mathrm{dl}$ & $88(14)$ & $84(13)$ & 0.13 & $92(11)$ & $87(11)$ & 0.01 \\
\hline $\mathrm{P}_{\mathrm{MAX}} / \mathrm{kg}, \mathrm{W} / \mathrm{kg}$ & $2.50(0.43)$ & $2.60(0.52)$ & 0.08 & $2.39(0.57)$ & $2.55(0.60)$ & $<0.001$ \\
\hline $\mathrm{VO}_{2}$ peak, $1 / \mathrm{min}$ & $3.21(0.63)$ & $3.35(0.74)$ & 0.04 & $3.21(0.78)$ & $3.32(0.67)$ & 0.28 \\
\hline HR80-140 W, / min & $123(15)$ & $116(14)$ & $<0.001$ & $119(14)$ & $115(12)$ & 0.06 \\
\hline Daily step counts & $7181(6482)$ & 8757 (5022) & 0.81 & 6947 (3092) & $6836(4558)$ & 0.87 \\
\hline
\end{tabular}

$\mathrm{BMI}=$ body mass index; $\mathrm{WC}=$ waist circumference; $\mathrm{RR}=$ resting blood pressure; $\mathrm{HDL}=$ high-density lipoprotein cholesterol; $\mathrm{P}_{\mathrm{AT}}=$ performance at the anaerobic lactate threshold; $\mathrm{P}_{\mathrm{MAX}}=$ peak ergometer performance; $\mathrm{VO}_{2}$ peak= peak ergometer performance; $\mathrm{HR}=$ mean heart rate at 80-140 $\mathrm{W}$ during ergometry . Study conducted in Munich, Germany, from April through July 2008.

Results are given in mean (SD).

Thirty participants (39\%) improved in all exercise parameters. Ninetyone percent showed general improvements in at least 3 metabolic parameters and six participants (7.8\%) showed improvement in all metabolic and anthropometric parameters. A reduction in waist circumference was seen in a majority (80\%) of participants.

\section{Website use and acceptance of intervention}

Of the 48 scheduled workouts, a total of (mean (SD)) 22.7 (10.6) were deactivated by the participants in the IG. The average length of these documented workouts was 54.6 (22.6) min. In addition, participants in the IG documented 9.5 (14.6) further activities with a mean length of 64.4 (65.8) min, leading to a total number of documented exercise sessions of 32.2 (19.6) with a mean length of 63.5 (23.0) min. Participants in the CG documented 43.1 (28.7) voluntary exercise sessions ( $p=0.15$ vs. IG) with a mean length of 72.7 (41.4) min ( $p=0.16$ vs. IG). In both groups, the majority of documented exercise sessions were endurance workouts with only 5 participants documenting more than 10 strength training sessions. The most popular activity in both groups was cycling, followed by walking, running, fitness training, and strength training. Ball sports were of minor importance.

Participants in both groups appreciated the intervention (IG: 4.1 (0.8), CG: $3.8(0.9) ; p=0.27$ ) and felt more active (IG: 4.1 (0.8), CG: $3.8(0.9) ; p=0.27)$. School grades for the intervention were $1.9(0.7)$ in the IG and $2.2(0.9)$ in the CG $(p=0.35)$.

\section{Discussion}

This study provides evidence that internet-delivered exercise recommendations at a work site intervention lead to significant improvements in both exercise capacity and metabolic risk profile in overweight, sedentary employees. However, no additional positive effects on these parameters were seen by providing a structured exercise schedule, as similar improvements can also be obtained by a non-structured website only providing standard advice.

Low physical fitness is an independent predictor of cardiovascular and all-cause mortality (Kodama et al., 2009), leading to recommendations of regular exercise for primary prevention in current guidelines (Graham et al., 2007; Haskell et al., 2007). The metabolic syndrome describes a cluster of risk factors for cardiovascular disease and diabetes with a rising prevalence worldwide. Reducing these risk factors is a pivotal task in primary prevention (Alberti et al., 2009). Besides predicting all-cause mortality, low exercise capacity is a strong and independent predictor of incident metabolic syndrome. It has been recommended to increase fitness levels in primary prevention particularly among those subjects who have already begun to cluster metabolic syndrome components (LaMonte et al., 2005a). Survival rates further improve with increasing exercise intensities (Franco et al., 2005), and more vigorous activity has been shown to particularly reduce diabetes risk in obese men (Siegel et al., 2009). Therefore, our study was designed to evaluate an internetbased exercise promotion recommending vigorous activities rather than promoting daily activity.

In contrast, the majority of web-based lifestyle interventions so far have focused on recommendations for moderate activities and behavior change, mainly determined by self-estimation using questionnaires or pedometers and accelerometers as objective measurements (Marcus et al., 2009; van den Berg et al., 2007). These approaches have only partly shown significant increases of daily activity (Carr et al., 2008; Hurling et al., 2007; Wanner et al., 2009), but direct measurements of physical fitness (e.g. aerobic exercise capacity) have not been assessed before. Wanner et al. (2009) compared a tailored website with different activity modules to a nontailored site offering general information and found an increase in self-reported physical activity in both groups, whereas accelerometer data did not change after intervention. Similar data were obtained by Spittaels et al. (2007a) in a workplace setting. However, these studies evaluated websites tailored to measures of behavior change. In our study, we chose a structured, individualized approach providing participants with specific heart rates for appropriate exercise intensities within a given schedule whereas "non-structured" was limited to general advice. Our results indicate that delivering precise and individualized exercise recommendations seems to be of minor importance at least in this setting.

The influence of similar studies on metabolic outcomes is equivocal. Carr et al. (2008) investigated the effect of an IT-delivered behavior change program on metabolic risk factors and found a reduction of waist circumference in the intervention group, but a more pronounced reduction of body fat percentage in the control group without active intervention. Aerobic fitness was also assessed using a walking test and increased in both groups. Van Wier et al. (2009) delivered lifestyle modification strategies via e-mail or telephone in a work place setting and observed minor but significant reductions of body weight and waist circumference for both intervention arms compared to a control group receiving lifestyle brochures. Our study contributes to these findings by showing significant effects of internet-delivered recommendations for vigorous exercise on waist circumference in both groups. However, this could again not be attributed to the structured, individualized approach. Nonetheless, the improvement of abdominal fat measure is important from a preventive strategy as visceral fat is strongly 
associated with metabolic and cardiovascular risk (Graham et al. 2007).

In general, lifestyle interventions are limited by high drop-out rates (Marcus et al., 2006; Toft et al., 2007). Likewise, in our study it took longer than anticipated to motivate 140 participants to register on the internet platform, despite sending invitations to 1,380 overweight and obese employees. However, when included, only $18 \%$ of participants actually quit during the exercise intervention period. This indicates a high acceptance rate among participants who start an exercise program. This was not dependent on body composition and risk profile as completers and drop-outs revealed similar data. Therefore the study results do not seem to be biased by drop-outs. Similar data were obtained by Buis et al. (2009) showing a response rate of only $15 \%$ despite inviting 47,000 candidates and drop-out rates of $21 \%$ during intervention. Overall, low response rates are a common problem in other similar intervention studies (Spittaels et al., 2007b; Verheijden et al., 2007; Ware et al., 2008). This shows that even the technological possibilities and unlimited availability of the internet is not sufficient to improve self-motivation. Therefore, it remains a major task for further research to define measures within internet-delivered exercise interventions which will induce improved participation and maintenance rates.

\section{Study limitations and strengths}

The duration of the program was 12 weeks, which might have been too short to detect significant differences between the two groups. Some of the differences between IG and CG may derive from the larger sample size in the IG. However, this seems of minor importance as neither exercise strategy showed clear superiority. Follow-up assessment would have provided information about the longer-term effectiveness of the program, which has been shown to decline over time in similar intervention studies (Carr et al., 2009). Statistically, we could not perform intention-to-treat analyses due to the lack of complete final data for the whole study population. However, to exclude a methodological bias, we performed sensitivity analysis with imputed conservative results for study drop-outs and did not find significant differences in outcome measures. A strength of this study compared to similar approaches is the high prevalence of male participants, which is, in turn, a limitation concerning the generalizability to women. However, the percentage of female participants is in line with the proportion of female employees in the company. Another strength of this study is the implementation of vigorous exercise into internet-delivered lifestyle interventions aiming at precise evaluation of aerobic capacity by lactate analysis during ergometry as well as assessing objective measures of maximal aerobic capacity $\left(\mathrm{VO}_{2}\right.$ peak) during intervention.

\section{Conclusion}

The results of this study provide evidence that interactive websites are applicable to improve exercise capacity and metabolic risk profile in overweight, sedentary subjects in a workplace setting. Interestingly, internet-delivered structured advice for exercise was not superior to a non-structured general advice, but this conclusion is limited due to low participation numbers and high drop-out rates. Therefore, further research is warranted to determine the particular setting that will promote participation and maintenance rates within internetdelivered exercise interventions.

\section{Funding}

This research was part of the SPRINT project (www.projekt-sprint. de). SPRINT is a joint project of the Technische Universität München and its corporate partners and was funded by the German Ministry for Research and Education (contract number FKZ 01FD0609). Study design, data collection, analysis and interpretation, writing of the report and submission of the results were not influenced by the funding source. This study was not financially supported by the BMW group; however, free access to facilities was enabled.

\section{Conflict of interest statement}

The authors declare that there are no conflicts of interest.

\section{Acknowledgments}

The authors greatly appreciate the logistical support of the BMW group, in particular A. Richter, MD, and J. Bischof, MD. Without their assistance this study would not have been possible. Furthermore, the authors gratefully acknowledge editorial assistance by C. Krcmar.

\section{References}

Ainsworth, B.E., Haskell, W.L., Whitt, M.C., Irwin, M.L., Swartz, A.M., Strath, S.J., O'Brien, W.L., Bassett Jr., D.R., Schmitz, K.H., Emplaincourt, P.O., Jacobs Jr., D.R., Leon, A.S. 2000. Compendium of physical activities: An update of activity codes and MET intensities. Med. Sci. Sports Exerc. 32, S498-S504.

Alberti, K.G., Eckel, R.H., Grundy, S.M., Zimmet, P.Z., Cleeman, J.I., Donato, K.A., Fruchart, J.C., James, W.P., Loria, C.M., Smith Jr., S.C., 2009. Harmonizing the metabolic syndrome: A joint interim statement of the International Diabetes Federation Task Force on Epidemiology and Prevention; National Heart, Lung, and Blood Institute: American Heart Association; World Heart Federation; International Atherosclerosis Society; and international association for the Study of Obesity. Circulation 120 , 1640-1645.

Buis, L.R. Poulton, T.A., Holleman, R.G., Sen, A., Resnick, P.J., Goodrich, D.E., Palma-Davis, L., Richardson, C.R., 2009. Evaluating Active U: An Internet-mediated physical activity program. BMC Public Health 9, 331

Carr, L.J., Bartee, R.T., Dorozynski, C., Broomfield, J.F., Smith, M.L., Smith, D.T., 2008. Internet-delivered behavior change program increases physical activity and improves cardiometabolic disease risk factors in sedentary adults: Results of a randomized controlled trial. Prev. Med. 46, 431-438.

Carr, L.J., Bartee, R.T., Dorozynski, C.M., Broomfield, J.F., Smith, M.L., Smith, D.T., 2009 Eight-month follow-up of physical activity and central adiposity: Results from an Internet-delivered randomized control trial intervention. J. Phys. Act. Health 6 , 444-455.

Dickhuth, H.H., Huonker, M., Münzel, T., Drexler, H., Berg, A., Keul, J., 1991. Individual anaerobic threshold for evaluation of competitive athletes and patients with left ventricular dysfunction. In: Bachl, N., Graham, T.E., Löllgen, H. (Eds.), Advances in ergometry. Springer, New York, pp. 173-179.

Franco, O.H., de, L.C., Peeters, A., Jonker, J., Mackenbach, J., Nusselder, W., 2005. Effects of physical activity on life expectancy with cardiovascular disease. Arch. Intern. Med. 165, 2355-2360.

Graham, I., Atar, D., Borch-Johnsen, K., Boysen, G., Burell, G., Cifkova, R., Dallongeville, J., De, B.G., Ebrahim, S., Gjelsvik, B., Herrmann-Lingen, C., Hoes, A., Humphries, S. Knapton, M., Perk, J., Priori, S.G., Pyorala, K., Reiner, Z., Ruilope, L., Sans-Menendez, S., Scholte op, R.W., Weissberg, P., Wood, D., Yarnell, J., Zamorano, J.L., Walma, E., Fitzgerald, T., Cooney, M.T., Dudina, A., Vahanian, A., Camm, J., De, C.R., Dean, V., Dickstein, K., Funck-Brentano, C., Filippatos, G., Hellemans, I., Kristensen, S.D., McGregor, K., Sechtem, U., Silber, S., Tendera, M., Widimsky, P., Zamorano, J.L. Hellemans, I., Altiner, A., Bonora, E., Durrington, P.N., Fagard, R., Giampaoli, S., Hemingway, H., Hakansson, J., Kjeldsen, S.E., Larsen, M.L., Mancia, G., Manolis, A.J., Orth-Gomer, K., Pedersen, T., Rayner, M., Ryden, L., Sammut, M., Schneiderman, N. Stalenhoef, A.F., Tokgozoglu, L., Wiklund, O., Zampelas, A., 2007. European guidelines on cardiovascular disease prevention in clinical practice: Executive summary. Eur. Heart J. 28, 2375-2414.

Haskell, W.L., Lee, I.M., Pate, R.R., Powell, K.E., Blair, S.N., Franklin, B.A., Macera, C.A. Heath, G.W., Thompson, P.D., Bauman, A., 2007. Physical activity and public health: Updated recommendation for adults from the American College of Sports Medicine and the American Heart Association. Circulation 116, 1081-1093.

Haslam, D.W., James, W.P., 2005. Obesity. Lancet 366, 1197-1209.

Hurling, R., Catt, M., Boni, M.D., Fairley, B.W., Hurst, T., Murray, P., Richardson, A., Sodhi, J.S., 2007. Using internet and mobile phone technology to deliver an automated physical activity program: Randomized controlled trial. J. Med. Internet Res. 9, e7.

Karvonen, M., Kentala, E., Mustala, O., 1957. The effects of training on heart rate; a longitudinal study. Ann. Med. Exp. Biol. Fenn. 35, 307-315.

Knebel, U., Esch, S., Pressler, A., Leimeister, J.M., Krcmar, H., 2009. Online, Set, Go Design and empirical test of an IT-based physical activity intervention. In: Newell, S., Whitley, E., Pouloudi, N., Wareham, J., Mathiassen, L. (Eds.), Information systems in a globalising world: Challenges, ethics and practices, pp. 1518-1530.

Knowler, W.C., Barrett-Connor, E., Fowler, S.E., Hamman, R.F., Lachin, J.M., Walker, E.A., Nathan, D.M., 2002. Reduction in the incidence of type 2 diabetes with lifestyle intervention or metformin. N Engl J. Med. 346, 393-403.

Kodama, S., Saito, K., Tanaka, S., Maki, M., Yachi, Y., Asumi, M., Sugawara, A., Totsuka, K. Shimano, H., Ohashi, Y., Yamada, N., Sone, H., 2009. Cardiorespiratory fitness as a quantitative predictor of all-cause mortality and cardiovascular events in healthy men and women: A meta-analysis. JAMA 301, 2024-2035. 
LaMonte, M.J., Barlow, C.E., Jurca, R., Kampert, J.B., Church, T.S., Blair, S.N., 2005a. Cardiorespiratory fitness is inversely associated with the incidence of metabolic syndrome: A prospective study of men and women. Circulation 112, 505-512.

LaMonte, M.J., Blair, S.N., Church, T.S., 2005b. Physical activity and diabetes prevention. J. Appl. Physiol. 99, 1205-1213.

Marcus, B.H., Ciccolo, J.T., Sciamanna, C.N., 2009. Using electronic/computer interventions to promote physical activity. Br. J. Sports Med. 43, 102-105.

Marcus, B.H., Williams, D.M., Dubbert, P.M., Sallis, J.F., King, A.C., Yancey, A.K., Franklin, B.A., Buchner, D., Daniels, S.R., Claytor, R.P., 2006. Physical activity intervention studies: what we know and what we need to know: A scientific statement from the American Heart Association Council on Nutrition, Physical Activity, and Metabolism (Subcommittee on Physical Activity); Council on Cardiovascular Disease in the Young; and the Interdisciplinary Working Group on Quality of Care and Outcomes Research. Circulation 114, 2739-2752.

Minderico, C. S, Silva, A.M., Keller. K. Branco, T.L Martins, S.S. Palmeira, A.L Barata, J.T. Carnero, E.A., Rocha, P.M., Teixeira, P.J., Sardinha, L.B., 2008. Usefulness of different techniques for measuring body composition changes during weight loss in overweight and obese women. Br. J. Nutr. 99, 432-441.

National Cholesterol Education Program (NCEP) Expert Panel, 2002. Third Report of the National Cholesterol Education Program (NCEP) Expert Panel on Detection, Evaluation, and Treatment of High Blood Cholesterol in Adults (Adult Treatment Panel III) final report. Circulation 106, 3143-3421.

Shephard, R.J., 1988. PAR-Q Canadian Home Fitness Test and exercise screening alternatives. Sports Med. 5, 185-195.

Siegel, L.C., Sesso, H.D., Bowman, T.S., Lee, I.M., Manson, J.E., Gaziano, J.M., 2009. Physical activity, body mass index, and diabetes risk in men: A prospective study. Am. J. Med. 122, 1115-1121.

Slootmaker, S.M., Chinapaw, M.J., Schuit, A.J., Seidell, J.C., Van, M.W., 2009. Feasibility and effectiveness of online physical activity advice based on a personal activity monitor: Randomized controlled trial. J. Med. Internet Res. 11, e27.

Spittaels, H., De, B.I., Brug, J., Vandelanotte, C., 2007a. Effectiveness of an online computer-tailored physical activity intervention in a real-life setting. Health Educ. Res. 22, 385-396.
Spittaels, H., De, B.I. Vandelanotte, C., 2007b. Evaluation of a website-delivered computer-tailored intervention for increasing physical activity in the general population. Prev. Med. 44, 209-217.

Toft, U.N., Kristoffersen, L.H., Aadahl, M., von Huth, S.L., Pisinger, C., Jorgensen, T., 2007. Diet and exercise intervention in a general population-mediators of participation and adherence: The Inter99 study. Eur. J. Public Health 17, $455-463$.

Tuomilehto, J., Lindstrom, J., Eriksson, J.G., Valle, T.T., Hamalainen, H., Ilanne-Parikka, P., Keinanen-Kiukaanniemi, S., Laakso, M., Louheranta, A., Rastas, M., Salminen, V., Uusitupa, M., 2001. Prevention of type 2 diabetes mellitus by changes in lifestyle among subjects with impaired glucose tolerance. N Engl J. Med. 344, 1343-1350.

van den Berg, M.H., Schoones, J.W., Vliet Vlieland, T.P., 2007. Internet-based physical activity interventions: A systematic review of the literature. J. Med. Internet Res. 9, e26.

van Wier, M.F., Ariens, G.A., Dekkers, J.C., Hendriksen, I.J., Smid, T., Van, M.W., 2009. Phone and e-mail counselling are effective for weight management in an overweight working population: A randomized controlled trial. BMC Public Health 9, 6.

Vandelanotte, C., Spathonis, K.M., Eakin, E.G., Owen, N., 2007. Website-delivered physical activity interventions a review of the literature. Am. J. Prev. Med. 33, 54-64.

Verheijden, M.W., Jans, M.P., Hildebrandt, V.H., Hopman-Rock, M., 2007. Rates and determinants of repeated participation in a web-based behavior change program for healthy body weight and healthy lifestyle. J. Med. Internet Res. 9, e1.

Wanner, M., Martin-Diener, E., Braun-Fahrlander, C., Bauer, G., Martin, B.W., 2009 Effectiveness of active-online, an individually tailored physical activity intervention, in a real-life setting: Randomized controlled trial. J. Med. Internet Res. 11, e23.

Ware, L.J., Hurling, R., Bataveljic, O., Fairley, B.W., Hurst, T.L., Murray, P., Rennie, K.L., Tomkins, C.E., Finn, A., Cobain, M.R., Pearson, D.A., Foreyt, J.P., 2008. Rates and determinants of uptake and use of an internet physical activity and weight management program in office and manufacturing work sites in England: Cohort study. J. Med. Internet Res. 10, e56. 